\title{
Comparative Analysis of Patient Education by Four Professions in the Netherlands and the United States*
}

\author{
Scott K. Simonds and Henk W. Kanters ${ }^{\mathrm{a}}$ \\ School of Public Health, University of Michigan, Ann Arbor, MI 48109 (U.S.A.) and ${ }^{a}$ Dutch Health Education Center, \\ Postbus 5104, 3502 JC Utrecht (The Netherlands)
}

(Received May 26th, 1989)

(Accepted November 17th, 1989)

\begin{abstract}
This cross-national comparison study of four health professions is based on review and analysis of professional policy documents and explores the ways these selected professions integrate and structure patient education as a professional function. Factors that are internal and external to each of these professions are discussed and compared between the two countries. Professional policy documents related to patient education in nursing, pharmacy, dietetics, and physical therapy are examined in light of changes in dominant concepts of care, changing norms of professional organizations, changes in professional preparation, changes in patient roles, changes in the organization of patient care, and the changes in the health care delivery environment. Differences and similarities between the Netherlands and the United States provide an impetus for developing hypotheses on cross-national developments in patient education and ways for several elements to interact and affect acceptance of and implementation of the patient education function by health professions.
\end{abstract}

S.K. Simonds, DrPH, Professor and Assistant Dean. H.W. Kanters, Drs, Research Director.

* Based on a paper read at the First World Congress on Allied Health, Helsinor, Denmark, June 11-15, 1988.
Keywords: Nursing; Pharmacy; Dietetics, Physical therapy.

\section{Introduction}

This paper examines how four health professions in two health care systems approach patient education. The country comparisons involve the Netherlands and the United States, two relatively advanced, postindustrial societies with quite different health care systems, different health manpower policies, health professions that have evolved in different ways under different conditions, and different approaches to patient education as a result.

Factors which appear to contribute to how the four selected professions in each country approach the patient education function are explored. The four professions are nursing, pharmacy, dietetics, and physical therapy. Their stated patient education functions and their preparation to carry out patient education are described based on a review and analysis of professional documents and health policy statements. This exploratory study is not based on time and motion studies, but rather consists more of a content analysis and interpretation of professional documents and policy statements generally available.

The four professions selected for this study were chosen because they are basic to the care 
of patients in medical care systems. The four professions were selected as "typical" health and allied health professions who work in a wide variety of settings, inpatient, outpatient, free standing services and who collaborate with physicians and other health professions to carry out patient education.

Based on the experience of each author in his own country, and observations of patient education functions in each other's country, both directly and through reviews of selected literature, it was "hypothesized" that there would be differences among and between the four professions; that there would be differences observed by country; that preparation for patient education would differ in each country for these four professions; and that the health care system, legal system and patient advocacy system would likely impact on patient education and its performance by the four professions differently in each country.

It was felt that in an exploratory cross national study such as this, one could gain an understanding of how different policy contexts, professional contexts, and academic preparation contexts might play a role in determining how an important function such as patient education might evolve.

For the purposes of this paper, patient education is defined as "a planned learning experience using a combination of methods such as teaching, counseling, and behavior modification techniques which influence patients' knowledge and health behavior. Patient counseling is an individualized process involving guidance and collaborative problem-solving to help the patient better manage the health problem. Patient education and patient counseling involve an interactive process which assists patients to participate actively in their care" [1].

The two countries studied here are similar in some ways, different in others. The Netherlands, with a population of 16 million inhabitants, can be considered to be one of the leading Western European welfare states with a centralized system of universal medical care. The United States, on the other hand, is a federated country with $\mathbf{2 4 0}$ million people, and much authority is vested in the fifty states and multiple medical and health care systems with only minimal health care insurance coverage available to selected populations. The centralization versus decentralization issue obviously affects health care, the health professions themselves, and patient education as well. Procedures and laws for professional licensure or certification are centralized in one country and not in the other, as an example. In the United States, different requirements for professional practice can exist in each of the 50 states.

More legal support for patient education probably exists in the United States than in the Netherlands. However, one finds in the Netherlands far more active and powerful patient advocate groups which serve to exert great pressure on policy actors to protect patients' rights than in the United States.

In both countries, the increasing cost of medical care has caused greater emphasis to be placed on out-of-hospital care but available insurance systems impact differently on this kind of care in each country. Thus more education of patients and families before they enter the health care system and after they leave will probably be required due to reduced lengths of stay - a problem more likely to be found in the United States than in the Netherlands currently, a fact which is likely related to the availability of insurance coverage for home care.

These and a number of other issues likely affect the development and provision of patient education in each country and by the four disciplines involved. It is anticipated that an analysis will serve to stimulate a number of cross-national comparisons and greater indepth study of issues involved.

In the following pages, a "glimpse" or overview of the four professions in each country is given, starting first with nursing, then pharmacy, followed by dietetics and physical therapy. Comparisons are then made among the groups and the two countries. The 
final sections deal with factors accounting for differences and implications for further study.

\section{Roles of four selected professions in two countries}

\section{Nursing (Netherlands)}

Two advisory but nevertheless authoritative documents on the nursing role were published by the Nursing Committee of the National Council of Public Health. In the earlier one "creating a therapeutic climate for patients" is described as one of three core dimensions of the nursing profession; educational care is referred to as emphasizing this dimension. Counseling, providing information and advice to patients and relatives are explicitly mentioned as essential elements within the nurses' task [2]. The second document delineates "vocational profiles" at two levels of competency. At both a "higher" and "lower" vocational level, nursing tasks are stated to encompass, amongst others, patient education and health education. To fulfill these tasks, nurses must possess such relevant knowledge and skills as: observational skills, interview and counseling techniques, skills in individual and group education, behavior modification techniques [3].

Studies indicate that nurses think patient education to be a very important aspect of their work and indeed nurses report to invest a lot of time in patient education. However, these data are not validated by observational research [4]. Informational contacts occur quite rarely, usually last only short period of time ( $1-2 \mathrm{~min})$ and usually are contingent on "technical" activities (like washing the patient, taking blood pressure, etc.).

However, in the last few years many hospitals have started innovative experiments in which nurses frequently are involved. Some developments are: the integration of patient education in nursing plans; the emerging role of clinical specialist nurse, who is responsible for specific tasks in patient education (i.e., the diabetic nurse, or oncology nurse); the role of patient education coordinator is sometimes allocated to nurses; often one or two nurses are involved in running the patient information center which hospitals tend to erect nowadays.

The larger part $(58 \%)$ of the nursing care in general hospitals is being delivered by registered nurses who follow a 3-year (mainly practical) in-service training, or by nursing students attending this type of training. Until now, patient education did not receive much attention in this vocational training. However, new regulations provide some entry points to focus on patient education within the in-service training and prevention and education are mentioned as required subject matter. Very recently a few projects have started, both at a regional and at a national level, aiming to improve the training in patient education within existing curricula.

Another trend concerns the development of post-graduate part time training courses in health education and patient education which registered nurses can follow at four institutes in the Netherlands.

In the Netherlands nurses may join three professional (union) organizations, although none of them really makes patient education a policy topic. Recently progress has been made in that they do participate in a multisectoral advisory committee, installed in 1984 by the Ministry of Health, to promote a coordinated "Policy Development on Patient Education". The Dutch Hospital Council is representing the hospital nurses in this committee, too.

\section{Home care nursing (The Netherlands)}

Providing curative and preventive nursing care as well as providing health education are two basic tasks of district nurses. Patient education nicely fits into this picture.

During the last $2-3$ years, both at a national level and at county level, Cross Associations which provide home nursing visits and other health and social services have placed a priority on health education and patient education. Policy documents on both 
issues have appeared [5,6]. In these, for example, recommendations relate to the systematic development of patient education in individual care; developing group oriented patient education; promoting cooperation between the Cross Associations and patient organizations; and carrying out policy supporting research. Several developmental projects have been initiated, particularly with respect to the educational care for heart patients, cancer patients, rheumatic patients, ethnic groups and the elderly. Large scale implementation is planned or carried out. The supply of relevant post-graduate training courses for district nurses can be anticipated to improve.

At this moment, little is known about how patient education is integrated into practice. First, administratively patient education is looked upon as an implicit type of nursing care which takes place within the context of other categories of care, such as hygienic care, activities-of-daily-living-support, etc. This "integration" reflects the difficulty in recognizing (and developing) patient education as a separate aspect of home care. Second, hardly any research has been carried out which focuses on nurse-patient interactions in the home care situation. Self-report data suggest that most of the individual contacts with patients bear on somatic care, administering medicine, and the like; some $20 \%$ of the contacts are intentionally directed towards psychosocial care, counseling and instruction [5]. Though most of the time is spent at somatic care, research shows that district nurses value much more the counseling and psychosocial aspects of their work [7].

Next to individual patient education district nurses play a role in group health education. Obviously, not all programs relate directly to patient education (i.e., programs for expectant parents), but some of them do, such as, courses for parents with asthmatic children, and conversation groups for heart patients or diabetic patients.

Most of the district nurses either attend a 4-year higher vocational training, or attend a 2-year application courses in public health care after finishing their in-service training in a general hospital. In both cases they have had a fair amount of training in health education and patient education, especially with subjects such as communication techniques, counseling, or nursing theory. Health education, as such, is not a compulsory subject.

\section{Nursing (United States)}

The profession of nursing is by far the largest health profession in size in the United States, numbering almost three million nurses and licensed vocational nurses. In general, for all employed nurses, each is responsible for and accountable to the patient and family for nursing care that includes patient and family teaching. Patient education has been integral to both the preparation of nurses and the practice of nursing for a long time, whether it is focussed on acute care, chronic care, rehabilitation, or more recently illness prevention or health promotion. The amount and kind of education provided is related, however, to the preparation of the nurse, the support given to patient education in the health care setting, and the nature of the health care setting itself, hospital care being quite different from home care settings, for example.

Patient education has been an integral component of nursing since the role of nurse was created, and increasingly patient education functions have been clarified in policies of professional organizations regarding preparation of nurses and the competencies expected of nurses as stated in standards of practice. "The Model Nurse Practice Act, formulated by the American Nurses Association in 1976, includes the words "health teaching" as one of the major functions of the registered nurse, and many nurse practice acts in the 50 states now include this wording" [8].

In the almost 1500 approved nursing preparation programs, nearly all students are likely taught something about teaching patients. The length of the program for prep- 
aration obviously influences the amount and kind of time available. The majority of nurses in the United States are diploma level nurses with somewhat less training than baccalaureate level nurses, although as the baccalaureate level is accepted more and more as the entry level [9] it is believed that more and better preparation of nurses in patient education is occurring.

Although general nurses standards of practice describe fairly well the teaching functions of nurses [10-12], many of the subspecialties within nursing increasingly describe the standards of practice to include patient education. Such organizations as the American Association of Critical Care Nurses, American College of Nurse-Midwives, National Association of Pediatric Nurse Associates and Practitioners, Nurse's Association of the American College of Obstetricians and Gynecologists, and Oncology Nursing Society and other nursing organizations, have stated that education of patients and their families is an integral part of nursing care [13-18].

The contemporary and emerging challenges for nurses in the area of patient education are perhaps affected as much by changes in health care financing and new health care technologies more rapidly and directly than any other factors. Efforts to contain rising health care costs have caused fewer patients to be admitted to medical care facilities, fewer patient days being spent in hospitals, and patients within hospitals being discharged who are much sicker than might have been the case earlier. Pressures to do required patient education before admission, and as immediate discharge planning is initiated, have added to the nurses problems in carrying out the needed education.

Nurses in the United States customarily learn to recognize the needs for patient education early in their training, are taught ways to assess learning needs, and are taught how to teach patients and families. They learn fairly early in their careers how to use selected educational methods and group techniques to support the teaching process. Increasingly they learn the social and behavioral sciences that serve as the foundations for the teachingcommunication function [19].

\section{Pharmacy (Netherlands)}

Three years ago the profession went through a series of discussions about a newly published document by the Royal Dutch Association of Pharmacy: "The tasks and functions of the public pharmacist" [20]. Pharmacists in the Netherlands, are seemingly at the crossroads as a profession. Either they go on developing themselves as shopkeepers, mainly distributing industrially produced medicaments and related articles, or they choose a care-taker perspective, in which they will serve as information centers on medicine on behalf of patients, the public and physicians.

This "vocational profile" of pharmacists does not speak of such mutually exclusive alternatives, but it is clear that more vigor than ever before is put into informative and educational functions. For instance, it is stated that "the pharmacist has to provide information to the patient necessary for successful therapy. This must not solely depend on the needs of the patient, but on the relationship between optimal medicine use and relevant information". All medicine will be delivered together with sound and easy to understand written or oral information. Explicitly it is proposed that patient education is a task of both physician and pharmacist and hence they will have to adjust their tasks mutually. Contrasted with this somewhat idealistic toned "vocational profile", average practice lags behind quite a bit, however.

Most pharmacists hardly interact with individual patients. This holds true for the hospital pharmacist, but also for his colleague working as a free-entrepreneur in primary health care. Their jobs typically include management, medication control, preparation of medicine, advising and consulting with physicians. Pharmacists tend to work "backstage", not vis-a-vis the patient which is done 
by the pharmacists' assistants. Patients in the Netherlands do not really expect pharmacists - the very experts on medicine - to give information. Rather, they prefer that their physician be the principal source of information about the medicine they have to take [21]. A familiar phenomenon in the pharmacies, which patients do recognize as an important source of information, is the "patient package insert" accompanying the medicine, which have been compulsory in the Netherlands since 1975. Recently, an impressive project was carried out with support of the Association of Pharmacy, in order to compile a "Medicine Encyclopaedia" which describes all (3800) obtainable medicaments in common sense language. This information is also available by way of a computer system; this opens possibilities to individualize written patient information in the context of medications.

Beyond the individual level, one can see a developing trend towards more patient and health education. Occasionally pharmacists give public lectures at meetings organized by patient organizations or professional groups and apparently there is a great need of information on side-effects of medicine, homeopathy and other topics. Since 1986 a quarterly "Patient Bulletin"' has been distributed in the pharmacies, containing information on medicine and pharmacy. It is also proposed to distribute videotapes, which patients can borrow and see at home.

Pharmacists receive minimally a 6-year university training. In 1983 new courses on giving drug information to patients were introduced in the curricula. This did not happen without much discussion and resistance, however [22]. Besides providing theoretical insights in the potential and limitations of patient education, these courses aim at enhancing skills in interpersonal communication, group education and writing educational materials. Recently also, postgraduate courses have been developed to train pharmacists in giving drug information to patients.

\section{Pharmacy (United States)}

Pharmacy practice has changed dramatically in recent years and is likely to continue to change considerably in the future. Pharmacy, formerly characterized as a profession largely of practitioners who owned pharmacies, who were self-employed, and who were primarily concerned with dispensing prescription drugs, is now far more oriented to clinical aspects of patient care, to assure rational drug use and to minimize adverse drug reactions. Practitioners are increasingly employed by health care organizations especially hospitals and focus this work more on clinical care than formerly [23-26].

Contemporary studies indicate that next to the physician the pharmacist is seen as the most frequent source of drug information by patients, and indeed, it is probably that the pharmacist is the most accessible of all health professionals and one from whom health information can be obtained by patients. Younger pharmacists not only are leading the way towards this more clinical orientation, but are also spending more time with patients compared with older pharmacists. All indications are that this trend will continue, and it is expected that as the ratio of pharmacists to population increase more time will be available.

Standards of practice require that pharmacists carry out a number of functions directed at informing and educating patients. Pharmacists are expected to confirm and clarity patient's understanding of medication dosage, frequency and methods of administration; advise patient of potential drug related reactions which may develop from use of medications; consult with patient to properly identity symptoms in order to advise patient on self medication; make recommendations regarding drug therapy to physician, patient and others concerned with patient's care; advise patients on personal health matters such as smoking or drugs; instruct patients in use of medical or surgical appli- 
ances, and participate in appropriate community or group education programs for patients or consumers [27].

Indeed, it is accepted today that one of the pharmacists key responsibilities if not the key responsibility next to dispensing medications is to provide authoritative usable drug information [28-31].

How well pharmacists are prepared for their education and communication functions is a moot point. A recent survey of 63 colleges of pharmacy indicate that two thirds of them offered classes in communication skills, which were mostly taught in dispensing and clinical clerkships. Of the 63 colleges, one third required classes in communication. Seven offered classes in patient education, two required them [32].

It is anticipated that the number of medications requiring prescriptions will increase over the next decades, and that many of the medications now requiring prescriptions will become over-the-counter medications. Likely the ratio of pharmacists to population will gradually increase by the year 2000 . The expansion of the elderly population will likely require greater attention to patient education and the recognized need for health promotion and wellness together with the greater use of home remedies, will place greater patient education responsibilities on the pharmacists than exist currently [33].

\section{Dietetics (Netherlands)}

Dietetics, a young profession, has been rapidly growing. In the last 15 years the number of working dietitians has doubled to nearly 1900 . However, compared with other (allied) health professions, it is still a small professional group and it is unlikely that further expansion will occur because of the political measures to economize on health care costs.

Over the last decade important changes may be noticed in the field of dietetics. First, the workfield has expanded from the hospital sector to extramural settings such as primary health care.

Along with this development, new educational tasks were added to the job of the dietitian from the curative task of giving dietetic advice to individual patients to the prevention oriented task of nutritional education in behalf of client groups. The most interesting trend, however, concerns basic assumptions and beliefs about the profession itself. Whereas the predominant mode of working used to be strictly prescriptive such as instructing patients what to eat or what not to, nowadays more of a counseling approach is advocated. For instance, a few years ago a new dietetic information system was developed, based on the principle that, within the limits of a prescribed diet, the patient himself (not the dietitian) has to determine his nutrition.

The above shows the intertwining of dietetics with patient education. This is underlined by a "vocational profile" outlined by the Dutch Association of Dietitians [34], which distinguishes two main functions for dietitians. The first one contains giving dietetic advice to individual patients, or sometimes patient groups: the dietitian is able to translate a technically stated medical diet, into a nutrition advice which the patient can understand and which is tailored to the individual situation.

The second main function is not a "paramedical" one in the sense that activities are performed in the field of medicine. Rather it refers to educational activities aimed to promote healthy nutrition behavior of groups or individuals, i.e. in the context of youth health care, or to prevent eating-related diseases. These health education or health promotion activities do occur in hospitals, but get a substantial weight only in extramural care, though. Moreover, in this sector a third main function is recognized, namely advising other health care workers such as district nurses on nutritional care $[35,36]$.

Professional groups instigated quality 
assurance experiments a few years ago. In another project, one is experimenting with peer group reviews. Regarding educational functions claimed by the profession, empirical data about how and when dietitians fulfill these functions in practice would be welcome. Until now no research has been done to investigate its educational performance.

Dietitians get a 4-year training at a "higher vocational"' level. Developments in the workfield, encouraged more attention in professional training paid to subjects such as prevention, education and communicative and didactic skills. Nevertheless, the National Cross Association, main employer of extramural dietitians, is providing an extra training program to dietitians who come to work in this field focussed on individual counseling, group education, and planning health education projects. Currently, training institutes are enhancing possibilities for students to differentiate between several training tracks, including a (paramedical) "dietetic" and a "nutritional expert" training track.

Several developments will probably influence the role of dietitians in the near future. Health promotion is a dominant concept in current Dutch governmental policies. It stresses individual life-style (including eating patterns) and environmental conditions as crucial factors related to health and prevention of diseases like heart disease and cancer. Quality control of nutrition as well as nutritional education appear to be promising tools to health promotion. Furthermore, the trend of shifting care from intramural to extramural settings, implies that patients will have to handle their diets by themselves at home. Consequently, dietitians will face clients with complex diets in hard to control situations (home settings). Stimulating and educating self-care will become more important.

\section{Dietetics (United States)}

The dietitian is viewed as the translator of the science of nutrition into the skill of furnishing optimal nourishment to people. As a translator of ideas into action the dietitian deals with nutrition information and education, counseling and guidance - all of which are intended to promote optimal nutrition among individuals or groups [37]. It is likely that the organizational goal of the American Dietetic Association to improve the ability of the public to make informed nutrition decisions is generally accepted as a goal of individual dietitians working in clinical and health care settings. The counseling and education of dietitian is directed at prescribed diets, health promotion, health maintenance and rehabilitation. Nutrition education is seen as a process by which nutrition information and beliefs, attitudes and the environmental influences about food can lead to practices that are scientifically sound, practical, and consistent with individual needs and available food resources.

The requirements for academic programs that prepare dietitians call for a general knowledge of cultural, socioeconomic, and psychological factors that influence food and nutrition behavior; basic concepts of effective communication, educational techniques and methods of teaching; and fundamentals of interviewing and communication [38].

It is recognized by the profession that many academic programs that prepare dietitians need to provide more emphasis on the arts, humanities, and behavioral sciences and communication [39]. One would anticipate increasing knowledge and skill in patient education to develop accordingly. There are 66 coordinated undergraduate programs and dietetic internships that prepare individuals for registration as dietitians [40].

More than half of the practicing dietitians are recent graduates with fewer than two years of experience in the field. While the majority of dietitians have only a baccalaureate degree, recent graduates are more and more likely to have master's or doctoral degrees.

Dietitians are giving increasing amounts of attention to health promotion and disease prevention. Increasingly, education of patients, their families, and the public is 
accepted as the professional responsibility of the dietitian. The increasing attention needed for the needs of the elderly and the increased amounts of care outside the hospital are placing new demands for educational skills by dietitians $[41,42]$.

\section{Physical therapy (Netherlands)}

Compared with other countries, the Dutch health care system has many physical therapists. Especially in the 1970 s, the profession expanded rapidly ( $150 \%$ increase). Nowadays there are 12,500 physical therapists, less then a quarter of them working in hospitals - the rest of them working extramurally as free entrepreneurs. From 1980 this volume expansion ended abruptly. Government and "sickness funds" took measures to restrict the number of professional activities and the settling down of new professionals.

In 1986 the Dutch Association of Physiotherapy prepared its first vocational description in which physical therapy was defined as "deliberately influencing a fellow-man whose functioning is impeded, by means of treatments as massage, physical exercise, and physiotechnical means, based on a positive interpersonal relationship" [43]. Contacts with a patient may be directed to prevention, to cure, as well to teaching a patient to cope with his disease or complaint. Several tasks are derived from this vocational description some of which bear on patient education. For instance, the physical therapist clarifies, if necessary, in order to increase the patients' insight, informing the patient about the disease and the treatment is acknowledged as a part of the treatment plan.

Currently no data are available on the way physiotherapists actually handle patient education. Descriptive research was not started until 1987. However, a conceptual problem may be involved here because physiotherapists probably supply patients with a lot of information, without labeling it as patient education. Usually, at least some explanation is given about what caused the patient's complaints and how these relate to certain habits or to environmental circumstances of the patient; also some advice or instruction is commonly given about physical exercises the patient has to perform, as part of the therapy. The main focus, however, is on treatment; patient education probably is just a by-product of this curative process.

Nevertheless, a more favorable climate with respect to patient education seems to be occurring. Articles on the subject are published nowadays in professional journals. Also it is more and more believed that patient education can possibly offer an answer to the wide spread problems of low patient compliance and high recidivism. Physiotherapists have come to participate in educational programs for specific patient groups. In such programs they fulfill a special role in the training of self care skills. Examples are the teaching of relaxation and breathing exercises to asthma patients, or the contributions inso called "pain schools" for paticnts suffering of chronic low back pain.

Students in this field in the Netherlands get a 4-year higher vocational training, including a 9-month practical apprenticeship. Only 2 out of 17 schools were shown to pay attention to patient education in a systematic way. Only those 2 schools had designed lessons in patient education and provided teaching material on this subject. Patient cducation therefore seems to be an area in which professional training is postponed to post-graduate courses, which are attended on a voluntary basis.

There exist several professional (umbrella) organizations for physiotherapists. Patient education seems to concern but a modest priority in these organizations. Advanced plans call for the creation of a national service, training and research organization the Dutch Institute for Physiotherapy and according to these plans, health education and patient education are two of the professional domains to be further developed by this Institute [44]. This is based on the assumption that the full value and potential of physical therapy have been systematically 
underestimated by policy makers. There is therefore a challenge to show the significance of the profession. "This holds especially for education and prevention", as can be illustrated easily with examples: promoting physical mobility and independence of the elderly; counseling of patients suffering from osteoporosis; reactivation of asthma or COPD patients; and prevention of recidivism at sporting injuries [45].

\section{Physical therapy (United States)}

Of the six major functions of physical therapists, patient and family education are emphasized as basic [46]. Of the four professions described in this paper, perhaps none has moved more rapidly in the United States in recent years to clarity its role and function in patient education than has physical therapy. Although patient education has always been a major method of caring for patients, because learning and relearning are obviously integral to the practice of physical therapy, one finds currently an expanded role for physical therapists in health promotion with a new emphasis on patient education.

Physical therapists are expected nowadays to recognize and apply concepts of health promotion, disease prevention, and health maintenance, as well as educate the patient and family regarding the physical therapy itself. They are expected to teach, counsel, and communicate to achieve this with individuals and groups of all ages. They are expected to inspire confidence in patients for getting and staying well and to be able to educate the patient regarding his/her life style as it affects health. In these tasks they are expected to utilize accepted principles of learning and methods of instruction [46-49].

In addition, standards of practice of the American Physical Therapy Association with its 40,000 members call for incorporating health promotion into practice, for effective communication with patients and their families about health promotion, with the use of effective learning experiences and good interpersonal relationships.
With the movement in health care from a medical model of health to a biosocial model, one finds changes underway in the accredited academic programs for physical therapists and programs for physical therapy assistants.

A current dilemma faced by the profession appears to be that the knowledge base of the field is outgrowing the current baccalaureate preparation, raising the questions of the need for the master's degree at the entry level into the profession. The potential impact of this issue on developing a more active patient education role is uncertain.

\section{Cross country comparisons}

On the whole the analysis of the documents on the four categories of health professions in the Netherlands suggests that they increasingly seem to commit themselves to the educational care of patients; that, until recently, vocational preparation in patient education has not been very extensive for most of these professionals; that in practice education of individual patients has been comparatively infrequent, or at least that little is known about the quality of performance of this aspect of patient care. Two of the professions which show the more favorable image are home care nursing and dietetics.

In each of the four professions interesting developments may be noticed, resulting in or reflecting a more favorable climate towards patient education. These changes relate to the policies and standards of the professional organization, to the professional or vocational preparation, and to the contextual support form the health care organizations.

Some of the factors that may possibly inhibit the expansion of the functions of patient education and the provision of leadership by these four disciplines are structural factors, since these disciplines are rather dependent on clinical decision making and activities of physicians. Their increased participation will require some further changes to also occur among the physicians and medical specialists. In addition, the 
professional (vocational) preparation of health workers does not appear to allow rapid changes due to the autonomy of professional schools and the overfilled curricula that now exists.

The role of government policies regarding patient rights, patient education, health promotion and home care appears to contribute currently to a changing environment which supports the expansion of patient education among these four disciplines. At the same time, however, the Dutch government is trying with increasing efforts to contain the rising costs of health care; so it hinders further volume expansion of physical therapy, pharmacy and perhaps also dietetics.

This ambivalency in governmental policy support, may be perceived as a challenge to the allied health professions, as they will have to find the right strategy (and of course the right coalition partners) to get their involvement in patient education fully recognized and appreciated. To achieve this, the support of patient groups or the public is indispensable.

The basic professional documents and accepted roles of the four professions in the United States generally support their providing some educational care of patients, although this varies among the four professions cited. The nursing profession has long accepted this responsibility, both in hospitals and in extended care or home nursing situations and has to some extent pursued this function with or without physician guidance. The preparation of nurses in most professional or vocational schools includes at a minimum the discussion of the importance of patient education and appropriate instructional techniques. The more advanced programs include basic education and psychological theory of communication, skills in needs assessment, interview techniques and instructional methods.

The patient education function has not been part of the pharmacist's job until rather recently, at least officially, and until the pharmacist became a more active member of the clinical care team. Only limited professional preparation for them has been available until recently. Expansion and upgrading of the role of the pharmacist with preparation to include patient education appears to be slowly gaining momentum.

Dietitians have for many years assumed a major education function vis-a-vis patients, and in recent years that the professional preparation programs have given it significant attention. Physical therapists have defined separate patient education functions as a part of routine physical therapy, but have expanded this role considerably with the greater attention currently being given to health promotion.

One could likely say, in fact, that the concept of health promotion has had in recent years a rather substantial influence on the expansion of the educational care of patients provided by pharmacists, dietitians, and physical therapists, more so than nurses who already have had a sizeable responsibility on patient education for many years.

Since 1966 with a major judicial decision in the United States affecting the legal status of institutional responsibility for the quality of medical care, and hence patient education, the health professions have received additional support to improve patient education. Policy statements of major provider institutions such as the American Hospital Association in 1972 and later and support from the President's Committee on Health Education in 1973 provided additional impetus for the improvement of patient education services. Current problems in dealing with health care costs have placed new burdens to educate patients and one would expect to see professions with health care responsibilities outside the hospital setting expand their efforts in this regard.

Government policies in the United States have not affected patient education directly so much as they have influenced it indirectly through policies dealing with cost containment or reimbursement for services. On the other hand, the professions themselves have 
taken fairly active roles to delineate policies regarding patient education and in turn have had some impact on the professional schools that prepare the four professions described here.

With a comparatively centralized health care system in the Netherlands, the government itself has made far greater efforts to stimulate the development of patient education than in the United States. Of course professionals are autonomous in the performance of their profession, so they may easily withdraw from "stimulating" governmental policies relating to the content - the vital part - of their jobs.

Because the United States is a very much more decentralized country, each of the 50 states has somewhat a freer hand in health matters, it would appear that the professions themselves have been more interested to take more active positions for themselves in this area than in the Netherlands. Legal decisions in the courts regarding malpractice and the policies of the large institutional health care providers such as hospitals and health maintenance organizations have been more reinforcing in this regard in the United States in contrast to the Netherlands.

In considering how one could advance patient education in the professions, it would seem that although research and evaluation would benefit the practice of providing educational care of patients in both countries, the role of government in health policy will likely continue to be more extensive in the Netherlands than in the United States. Many segments of the policy environments in both countries appear to be encouraging the expansions of the patient education, although countervailing factors are operating simultaneously, i.e. in the United States there is currently less fiscal policy encouragement at the Federal level and in the Netherlands the numbers of health professions is regulated more strictly.

The concept of health promotion which proved to be a promising one and has already incorporated into the ethos of health professions in the United States may someday begin to affect these professions in the Netherlands in the same way.

\section{Discussion}

Throughout the past 25 years in both countries, the basic beliefs and values underlying patient care and patient education have changed, and the contexts within which patient care and patient education are provided has also shifted. Patient education as provided by the four professions has also shifted. Some of the key factors that have affected these contexts have been described elsewhere [50,51], but include the following at a minimum:

\section{Changes in the dominant concepts of patient care}

A dominant concept of patient care has evolved from what can be called a "somatic" care concept, through a "psychosocial" concept to what can be now termed a combined "humanistic-health promotion" concept. To speak of a dominant concept of care suggests that it acts as a guiding principle in many disciplines and in many dimensions of care. This is true not only for the four professions described here, but for other professions as well and for the health care system more generally including its policy and administrative levels. It would perhaps be extending the point too far to say that the "humanistic-health promotion" concept is the driving force in health care in both countries, especially with tertiary and long term care demands of aging populations, but it is a force recognized in both countries as having increasing weight in how health care is provided. With the increasing recognition that a large number of medical practices are not scientifically valid and that few standards for practice exist in both countries, acceptance of a "humanistic health promotion model" is at least a low cost and at best a "do no harm" option that is being accepted and utillzed by health care providers. Not only is 
the patient the focus of this approach, the community is now included.

Changing norms of professions and professional organizations

Closely related to the shifting "mission" of health care are the self-imposed beliefs, norms, and practices of professional organizations and individual health professions about their contributions to patient care. Professions go about "charting their turf", developing standards of practice, developing policy papers and "vocational profiles", and establishing knowledge bases supposedly unique to their separate fields of practice [52]. Consensus within a profession is needed in order to set these roles and standards, but it is clear that large differences may exist between individual members and overlaps occur among the professions themselves. In patient education, clearly there is considerable overlap among the four professions in terms of function, although in the content of patient and the location where the service is provided differ considerably among the four professions studied here. The major overlaps appear to occur between nursing and the two professions of dietetics and pharmacy, although this appears more true on an inpatient basis than on an outpatient basis. Little overlap appears in the community context.

\section{Changes in professional preparation}

The professional skills needed to fulfill patient care obviously shift with changes in dominant concepts of care. Professional preparation, however, is sometimes ahead of practice and sometimes behind actual practice requirements. Academic and vocational preparation institutions change slowly, and professional curricula are not always synchronized with the demands of practice. For the four professions above, perhaps nursing more than the other three has been more alert to and ready to move on its professional preparation programs to accommodate issues related to patient education. The other threc are seen as "emerging" more recently. In a sense there is less "patient education baggage" in the curricula of the other three professions, hence adding knowledge and skills to the curricula may be easier than removing it or even updating what is already there.

\section{Changes in the patient role}

How a patient is expected to behave is partially defined by the role "assigned" to professionals, but the role appears to be increasingly influenced by other values and norms, particularly the idcas cxpressed by society or by patient advocate groups. According to the somatic concept of care, the patient is seen as rather submissive. As one moves into a psychosocial care concept, which stresses personal contact and better two way communication, the patient still has little control over the care provided. However, in the humanistic-health promotion model, a rather heavy burden of initiative and responsibility is placed on the patient, with the task of keeping well and managing self-care placed directly on the patient's shoulders or his family's. In fact, the educational tasks are increased when the patient is expected to play a larger role in his care. These patient role changes have had impacts on each of the four health professions described. Each has moved to give the patient more control over his/her own life as a patient. In a sense, one can see a gradual 'downward shift in technology' over time, from physicians to allied and other health professions, then from both allied and other health professions to patients and even to the community. It is an interesting question to consider how much the health professions are willing to allocate to patients in a time with mixed economic and political forces. Should one "give away" more to patients because costs are rising and it would be more economical to do so or should one preserve in ones professional domain as much as possible? Preserving the "technology" of ones profession may possibly mean more revenue. Because there is a surplus of certain groups of health manpower perhaps tasks must be pre- 
served as the right of ones profession to administer in order to assure there will be enough work for all.

\section{Changes in organization of patient care}

It is clear that a hospital has to be organized in such a way as to make certain care concepts operational. For example, patient centered care, another often used label to denote psychosocial care, requires a care structure that is tuned to the patient which in turn requires an integration of tasks to facilitate contact between patient and health professional as well as a high degree of coordination and cooperation among professions. This is quite different from the dualized system that is suited to somatic care concept where one finds autonomous and individual professionals operating "solo". Such a model supports the medical specialists on one side of the hierarchy and the hospital bureaucracy on the other. In the humanistic-health promotional concept, far greater integration among members of the health care team is required with patient and family education tasks increased in order to accommodate the patient and family as a member of the health care team itself. More education in toto is required to enable the patient and family to be self-sufficient and manage more and more self-care routines on their own. Thus time, space and altered relationships in the system are required to make room for these new demands.

\section{Changes in the external environment}

Clearly a predominant concept of care develops in interaction with a broad social environment with forces, which in turn may be influenced by the emerging or shifting concepts of care. For example, governmental policies in health care such as cost containment, standards of practice and quality assurance interact with legislative, funding, legal and jurisdiction issues and patients' rights. All these add up to a fluid but powerful set of forces in the community and in society that interact with patient care concepts and indeed influence them and are influenced by them. Thus the four health professions discussed here exist in an enormously complex environment with a powerful set of factors that interact with them and their self-determination, and hence their decisions enlarge or expand their functions in the area of patient education and improve the preparation and practice of those involved in providing it.

\section{Differences between The Netherlands and The United States}

The framework above reveals some noticeable differences between the two countries and the four health professions. For example, it appears that the American organizations representing these four professions have stated their roles in patient education much earlier and far more explicitly than their Dutch counterparts have done. The process has included clarification of and even reconceptualization of some of the core tasks of the profession itself including patient education. This clarification and commitment in the Netherlands has occurred only in recent years. Further the development of standards of practice by the professions themselves in regards to patient education have evolved much further in the United States than in the Netherlands. In fact, such standards of practice in patient education hardly exist for any professions in the Netherlands currently.

In terms of professional preparation in knowledge and skills to carry out patient education, organized professions in the United States have taken responsibility and in fact the initiative to integrate concepts of patient education into the curricula of professional preparation programs. Some of the work on these curricular issues appears to be "migrating" towards the Netherlands, and the beginnings can be seen in some of the professional preparation programs there, particularly in nursing. On the other hand, there appear to be more post graduate or continuing education programs on patient education available to nurses in the Dutch system, which may reflect that patient education is at an "add 
on" stage, which may precede its integration into the primary or initial preparation programs.

In regard to the patient's role, only modest efforts by the professions themselves to influence the role of patients were found in documents available. However, the Dutch National Cross Association, an umbrella institution involved in extramural care has developed a major policy that directs its member organizations and staff in nursing and dietetics particularly to plan patient education in cooperation with patient organizations which indicates a tangible effort in this regard. It is worth noting, per haps, although not studied in detail here, that there appear to be many more and far more active patient organizations in the Netherlands than in the United States, and it is interesting to reflect that these groups may provide the equivalent force to influence the health care system and its providers which have been granted through legal rights for patients in the United States. It is interesting to speculate whether the professions in the United States have attempted to co-opt the patient in this process, whereas the Dutch system provides a more advocate-adversarial relationship which requires more active negotiation of the "space" between patients and providers.

Between each country, considerable variation exists in how each profession can be "accessed" by patients. One of the striking contrasts is seen in the work of the pharmacist. The clinical tasks of the American pharmacist enable him to participate more actively in patient education than the "controlling" tasks of his Dutch colleagues. In another example, it often appears that in American hospitals nursing tasks are commonly structured in such a way as to have the nurse delegate total care of a number of patients, a task for which she is accountable. Although this notion of "primary nursing" occurs in several Dutch hospitals, it is not true in the majority of them. Thus educational care of patients, in a sense, is not focussed in the tasks of the key nurse providing care, but rather is more diffused in the Dutch nursing system, with the likely result less patient education actually gets done by nurses in hospitals in the Netherlands.

However, on an ambulatory or out-ofhospital basis, the Dutch system has traditionally been strongly structured and adapted for the development of patient education and self-care. Since the Dutch health care system has been more focussed to keeping patients out of the hospital than the system in the United States, it is obvious that education for self-care would naturally be far more integrated into the home nursing enterprise.

Another striking difference exists between the two countries in the area of legal procedures applying to malpractice, for in the American legal context, it is far easier to bring a legal suit against providers, both individual professionals and health care institutions, such as hospitals. There would appear to be in the United States major efforts to reduce malpractice suits through improved communication between providers and patients, and indeed, there are professional and institutional commitments often to avoid misunderstandings and for articulating standards of care that require effective communications with patients. Such clear cut responsibilities do not exist in the Dutch health care context, where it is difficult at best to even get a complaint for poor care heard in a public court. Most complaints, if not dismissed, are handled by an internal disciplinary court. If the patient succeeds in this instance, he customarily does not get any payment. Rather the professional is reprimanded. Thus what the American patient can achieve through legal action is not yet permitted for Dutch patients, which perhaps reinforces the need for strong patient rights groups in the Netherlands. With the increased concern about 'informed consent' doctrine in the Netherlands, it is likely some of these issues will be tested further in legal ways.

In all these areas, it is a time of enormous change in both countries and in the design of health care itself. On one hand the Dutch sys- 
tem appears to be moving towards the American system by encouraging a more liberal and competitive system particularly in an effort to control costs. On the other hand, one begins to see the American system "edging" towards the Dutch system in its concern with accessible and available care for all with some sort of prepayment process. One finds the appeal of the Canadian health care system increasingly attractive to Americans, for example, with its provision of universal coverage.

In all these changes, there is little doubt that the four professions will be tested and affected, as will the total systems themselves. Likely patient education will need to be extended and improved in both systems to accommodate the changes and to engage the patient increasingly as an active partner in self care and in taking responsibility for promoting his/her own health.

\section{Summary}

This exploratory study highlights the value of examining several health professions and a single function and how it is structured in those professions in two countries. The approach requires each profession to be viewed within much larger social-organizational contexts and the function of patient education to be viewed with somewhat less "country bias" than perhaps it ordinarily is seen.

From a policy framework, such an analysis provides options to enhance patient education in one country that have yet to be developed in the other (as for example enhancing patient groups in the United States to provide greater political force as is done in the Netherlands).

From a research view, such an analysis begins to suggest models that might be employed to study organizational change and health care concepts cross culturally that impact on the patient education function. It suggests also the importance of examining the structure of patient education, as well as process, particularly within institutions and professions.
The concept of the patient education in institutional settings and in extramural settings and the evolving acceptance of health promotion as an important goal for health professions applied to the stage for the advancement of patient education in both countries. The burden of illness, particularly chronic illness among the elderly, the rising health care sosts, and the need to have individuals take greater responsibility for their own care and health, focuses these concerns on patient education in both countries.

\section{References}

1 Bartlett EE: At last, a definition. Editorial, Patient Educ Couns 1985; 0: 323.

2 Centrale Raad voor de Volksgezondheid: Taak van de Verpleegkundige (Task of the nurse). Rijswijk: Ministerie Volksgezondheid en Milieuhygiene, 1974.

3 Nationale Raad voor de Volksgezondheid: Advies Verpleegkundig beroepsprofiel (Advice Vocational Profile of the Nurse). Zoetermeer: Ministerie van WVC, 1984.

4 Kanters HW, Zonneveld T van: Patientenvoorlichting op de verpleegafdeling (Patient education at the nursing ward). GVO/Preventie 1986; 7: 22-32.

5 Nationale KTuisvereniging: Wuiswerk en GVO, nieuwe trends (Cross Assocations and Health Education: new trends). Bunnik, 1986.

6 Nationale Kruisvereniging: Patientenvoorlichting in het kruiswerk (Patient education by Cross Associations). Bunnik. 1986.

7 Kerkstra A, Verhaak PFM: Wijkverpleging (Home nursing). In: Sluijs EMJ, Zee J van der, eds. Overzichtsstudie onderzoek eerstelijn (Review Extramural Research). Utrecht: NIVEL, 1985.

8 Bartlett EE: Historical glimpses of patient education in the United States. Patient Educ Couns 1986; 8: 141.

9 United States Bureau of Health Professions: Report to the President and Congress on the status of health personnel in the United States 1986; 10;1-78.

10 American Nurses' Association: Standards, Nursing Practice. 1973.

11 American Nurses' Association: The Professional Nurse and Health Education, 1987.

12 American Nurses' Association: Educational Preparation for Nursing; Selected Nursing Competencies, 1980.

13 American Nurses' Association and National Association of Orthopaedic Nurses: Orthopaedic Nursing Practice; Process and Outcome Criteria for Selected Diagnoses, 1980.

14 American Nurses' Association: Scope of Primary Nursing Practice for Adults and Families; Functions and Qualifications for an Occupational Nurse in a One-nurse Service; Concepts of Community Health Nursing Practice. 1987. 
15 American Society of Opthalmic Registered Nurses with the American Academy of Opthamology: Standards of Ophthalmic Nursing Practice, 1985.

16 Emergency Nurses Association: Standards of Emergency Nursing Practice, 1983.

17 Nurses' Association of the American College of Obstetricians and Gynecologists: Standards for Obstetric, Gynecologic and Neonatal Nursing, 3rd edn, 1986.

18 Oncology Nursing Society: Outcome Standards for Cancer Patient Education, 1982.

19 Redman BK: The Process of Patient Teaching in Nursing. St. Louis: C.V. Mosby, 1980.

20 Koninklijke Nederlandse Maatschappij ter bevordering van de Pharmacie: De taken en functies van de openbare apotheker (Task and functions of the public pharmacists). s.1., 1985.

21 Groenewegen PP: Aptheker (The Pharmacist). In: Sluijs EMJ, Zee J van der, eds. Overzichtsstudies Onderzoek Eerstelijn. Utrecht: NIVEL, 1985.

22 Jong LTW de, Blom A, Wieringa N: Voorlichtingskunde voor de apotheker (Education on drug information for Pharmacists), Pharm Weekbl 1986; 121: 510-13.

23 American Association of Colleges of Pharmacy: Pharmacy in the 21st Century: Executive Summary, 1984.

24 American Society of Hospital Pharmacists: Proceedings, Research and Education Conference, 1985.

25 American Society of Hospital Pharmacists: Statement on pharmacist-conducted patient counseling. Am J Hosp Pharm 1976; 33: 644-645.

26 American Society of Hospital Pharmacists: Statement on Clinical Functions of Institutional Pharmacy Practice, 1980 .

27 Kalman SH, Schlegel JF: Standards of practice for the profession of pharmacy. Am Pharm 1979; 19: 3 .

28 Ascione FJ: The Pharmacists as Patient Educator: Course Outline. University of Michigan College of PharInacy, 1987.

29 Carney JC: The pharmacist's duty to counsel. US Pharm 1987; October: $81-88$.

30 Communication with patient-drug information. J Am Pharm Assoc 1977; 17: 464.

31 Health Education-Pharmacist's Responsibility. J Am Pharm Assoc 1987; 7: 323.

32 Ascione, FJ: Teaching of patient education in colleges of pharmacy. Unpublished survey, University of Michigan College of Pharmacy, 1983.

33 United States Bureau of Health Professions: Report to the President and Congress on the status of health personnel in the United States. 1986; 8: 1-17.

34 Rapport Werkgroep Dieetvoorlichtingssystemen (Report of the task force Dietetic Advice systems) den Haag: Voorlichtingsbureau voor de Voeding, 1986.

35 Nederlandse Vereniging van Cietisten: Profielschets van de Nederlandse dietist (Profile of the Dutch dietitian). Oss, 1979.
36 Nationale Kruisvereniging: Dietist bij een kruisvereniging: algemeen profiel van de functie (Dietitian in Cross Association: general function profile). Bunnik, 1988.

37 American Dietetic Association:. Accreditation/Approval Manual for Dietetic Education Programs, 1987.

38 American Dietetic Association: Standards of Education, 1985.

39 American Dietetic Association: Policy Statement on Nutrition Education for the Public. Am Diet Assoc Rep August 1985; 8: 980-982.

40 United States Bureau of Health Professions: Report to the President and Congress on the status of health personnel in the United States, 1986; 12: 8-10.

41 Study Commission on Dietetics, American Dietetic Association, The Profession of Dietetics, 1985.

42 United States Health Resources Administration, Role Delineation for the Field of Clinical Dietetics/Final Report HRA-Contract 232-72-0074, December 1980.

43 Nederlands Genootschap Fysiotherapie: Beroepsomschrijving Fysiotherapeut (Vocational profile Physical therapist). Amersfoort, 1986.

44 Polman E, Iaspers A: De voorlichting doorgelicht: patientenvoorlichting in de opleiding fysiotherapie (Patient education in the professional preparation of the physical therapist), Maastricht, 1985.

45 Stitchting Wetenschap en Scholing Fysiotherapic: Naar een ondersteunings-structuur voor de fysiotherapie (Towards a support structure for physical therapy). Amersfoort, 1987 .

46 American Physical Therapy Association, Fact Sheet, 1987.

47 United States Bureau of Health Professions, Report to the President and Congress on the status of health personnel in the United States, 1987; 12: 15-17.

48 American Physical Therapy Association: Proposed Standards for Accreditation of Education Programs for the Physical Therapist, 1986.

49 American Physical Therapy Association: Physical Therapy Education and Society Needs: Guidelines for Physical Therapy Education, November 1984.

50 Boekholdt M: Care concepts and strategies for innovation. In: Proceedings How to Make Bettter Use of Available Resources within European Health Services. Danish Hospital Institute, 1982.

51 Kanters HW: Veranderling van routine: patientenvoorlichting in orgainsatie psychologisch pespectif (changing routines: patient education within the perspective of organizational psychology). GVD/Preventie 1988; 2: 95 $-107$.

52 Friedson E; Professional Powers: A Study of the Institutionalization of Formal Knowledge. Chicago: The University of Chicago Press, 1986. 